\title{
Celiac disease in children: is it a problem in Kuwait?
}

This article was published in the following Dove Press journal:

Clinical and Experimental Gastroenterology

29 December 2014

Number of times this article has been viewed

\section{Wafa'a Al-Qabandi' \\ Eman Buhamrah² \\ Dalia Al-Abdulrazzaq' \\ Khaled Hamadi ${ }^{2}$ \\ Fawaz Al Refaee ${ }^{3}$}

'Department of Pediatrics, Faculty of Medicine, Kuwait University, Kuwait; ${ }^{2}$ Department of Pediatrics, Al Amiri Hospital, Kuwait; ${ }^{3}$ Department of Pediatrics, Al Adan Hospital, Kuwait

All authors contributed equally to the study

Correspondence: Wafa'a Al-Qabandi Department of Pediatrics, Faculty of Medicine, Kuwait University, PO Box: 24923 Safat 13 | 10, Kuwait Tel +96599027291

Fax +965 25338940

Email walqabandi@gmail.com
Background: Celiac disease (CD) is a chronic inflammatory disease of the small intestine triggered by gluten ingestion. The objective of this study is to describe our experience with CD children in Kuwait.

Methods: The records of children with CD seen in the pediatric gastroenterology unit between February 1998 and December 2010 were retrospectively reviewed. Patients were referred because of symptoms or positive CD antibody screening of a high-risk group (type 1 diabetes and Down syndrome).

Results: Forty-seven patients were diagnosed: $53 \%$ were symptomatic and $47 \%$ were identified by screening. The median age at diagnosis was 66 (range 7-189) months. All cases were biopsyproven except one. The symptomatic patients were significantly younger than those identified following screening $(P<0.004)$. In the whole group, 66\% were females and $77 \%$ were Kuwaitis; $9 \%$ had a positive family history of CD. The estimated cumulative incidence was $6.9 / 10^{5}$. The median duration of symptoms before diagnosis was 8.5 (range 2-54) months. Failure to thrive was the most common presenting complaint (72\%) followed by diarrhea (64\%) and abdominal distension (56\%). Atypical manifestations were seen in $60 \%$ of patients. Underweight and short stature were confirmed in $19 \%$ and $17 \%$ of patients, respectively. Overweight and obesity were detected in $14 \%$ and $6 \%$, respectively. CD serology was based on a combination of antiendomysial and antigliadin antibodies. The median follow up was 24 (range 12-144) months. All patients were commenced on a gluten free diet, but good compliance was only achieved in $78 \%$.

Conclusion: The low frequency of childhood CD in Kuwait could probably be attributed to either an underestimation of the atypical presentations or failure of proper screening. Also, adherence to a gluten free diet is a major problem in our population.

Keywords: celiac disease, children, Kuwait

\section{Introduction}

Celiac disease (CD) is a chronic inflammatory disease of the small intestine triggered by ingesting gluten-containing food in genetically predisposed individuals. Population-based studies suggest that CD affects $0.5 \%-1 \%$ of the general population in the Western world. ${ }^{1,2} \mathrm{CD}$ is also common in the developing world; ${ }^{3}$ hence, it is now considered a public health problem worldwide. With the introduction of more sensitive and specific serological tests, its prevalence in the Middle East was found to be similar or even higher than in Western countries. ${ }^{4}$ It has however been poorly reported from the Arabian Gulf with studies from Saudi Arabia and Oman. ${ }^{5,6}$ CD was reported in Kuwait in 1987 when Khuffash et al described 20 affected children and estimated the prevalence as 1:3,000 births. $^{7}$ Another report showed that CD was responsible for $18.5 \%$ of protracted diarrhea in children in Kuwait. ${ }^{8}$ 
Nevertheless, over the past 25 years, there have been no studies describing the disease in our children and it has never been reported in the adult population. In this paper, we describe our experience with CD in children in Kuwait and compare its presentation with that previously reported in the country as well as in other populations.

\section{Subjects and methods}

After obtaining Ministry of Health ethical committee approval, the records of all patients with CD seen in the pediatric gastroenterology unit between February 1998 and December 2010 were retrospectively reviewed. In addition, a letter was sent to the Pediatric Council representing pediatric departments of all governmental hospitals requesting referral of all CD patients to our unit. The gastroenterology unit, located in Al Amiri Hospital, was the only center serving pediatric gastrointestinal problems in Kuwait during the study period. The patients were referred based on suspicious symptoms (symptomatic) or positive $\mathrm{CD}$ antibody screening (screened) among an at-risk group. CD diagnosis was based on the North American Society of Pediatric Gastroenterology, Hepatology and Nutrition criteria. ${ }^{9}$ Data obtained from the files included: demographic characteristics, clinical presentation, associated autoimmune diseases and family history of $\mathrm{CD}$ or other autoimmune disease. Also, anthropometric measurements were documented including weight (in kilograms), height (in centimeters), and body mass index (BMI). The measurements were converted to age-specific $z$ scores derived from Centers for Disease Control and Prevention (CDC) growth charts. ${ }^{10}$ World Health Organization growth charts were not used, as they had not been adopted in all Kuwait hospitals at the time of writing this report. For children younger than 2 years, weight-for-height percentiles were used in lieu of BMI. Subjects were grouped into 4 categories according to BMI percentile, as defined by the CDC charts: underweight ( $z$ score $<-1.64$, or $<5$ th percentile for age); normal weight ( $z$ score -1.64 to +1.04 , or 5 th to $<85$ th percentile); overweight ( $z$ score $>1.04$ to 1.64 , or 85 th to 95 th percentile) and obese ( $z$ score $>1.64$, or $>95$ th percentile) ${ }^{11}$ Short stature was defined as height $z$ score $\leq-2$. Laboratory findings including hematological and biochemical analyses were also documented. Anemia, hypoalbuminemia and hypocalcemia were defined as hemoglobin, albumin and calcium levels below $11 \mathrm{~g} / \mathrm{dl}, 35 \mathrm{~g} / \mathrm{L}$ and $2.2 \mathrm{mmol} / \mathrm{L}$, respectively. Elevated liver enzymes were defined as alanine aminotransferase (ALT) and aspartate aminotransferase (AST) higher than 60 and 40 IU/L, respectively. CD serology including a combination of anti-gliadin antibodies (AGA) using ImmuLiza ${ }^{\mathrm{TM}} \mathrm{IgG}$ or
IgA-AGA test kits (Immco Diagnostics, New York, USA) and antiendomysial antibodies (EMA) using $\mathrm{ImmuGlo}^{\mathrm{TM}}$ endomysial IgA antibody (Immco Diagnostics) or Nova Lite ${ }^{\circledR}$ kits (INOVA Diagnostics, San Diego, CA, USA) was performed in all patients. Anti-tissue transglutaminase antibody (tTG) was available in our laboratory in the last year of the study period, hence, was performed in 9 cases only by ImmuLiza (Immco Diagnostics). EMA was reported as positive when there was fluorescence of the endomysium of smooth muscle bundles. The cut-off values of tTG, IgA-AGA and IgGAGA were $20 \mathrm{U} / \mathrm{mL}, 23 \mathrm{U} / \mathrm{mL}$ and $28 \mathrm{U} / \mathrm{mL}$, respectively.

All patients underwent an upper GI endoscopy for tissue diagnosis except one because of parental refusal. Multiple biopsies (4-6) were obtained from the second and distal parts of the duodenum in all patients. Few patients had additional bulb biopsy especially at the end of the study period. The pathology reports were reviewed and CD diagnosis was established based on Marsh criteria. ${ }^{12}$

\section{Statistical analysis}

The data were analyzed with statistical package for social sciences (SPSS) software (version 21) and data were expressed as mean \pm standard error of the mean (SE) and/or median. Intergroup differences were studied using independent-samples Kolmogorov-Smirnov and/or Pearson chi-square tests as appropriate. A $P$ value of $\leq 0.05$ was considered significant.

\section{Results}

Forty-seven CD patients were diagnosed during the study period (symptomatic: 25 , screened: 22). The screened group included 19 patients with type 1 diabetes (T1D), 2 with Down's syndrome and 1 with both disorders. The median duration of diabetes before $\mathrm{CD}$ diagnosis was 36 months (range: 2-130). Seventy seven percent of the patients were diagnosed in the second half of the study period, ie, after 2005. As shown in Table 1, females predominated

Table I Demographic features of CD patients

\begin{tabular}{llll}
\hline & $\begin{array}{l}\text { Symptomatic } \\
\text { (N: 25) }\end{array}$ & $\begin{array}{l}\text { Screened } \\
\text { (N: 22) }\end{array}$ & $\begin{array}{l}\text { Total } \\
\text { (N: 47) }\end{array}$ \\
\hline F:M & $18: 7$ & $13: 9$ & $31: 16$ \\
Nationality (K/NK) & $20 / 5$ & $16 / 6$ & $36 / 11$ \\
Age range (months) & $7-152$ & $36-189$ & $7-189$ \\
Median age (months) & 24 & 92 & 66 \\
Associated disease & - & $4(18 \%)$ & $4(9 \%)$ \\
FH CD & $3(12 \%)$ & $1(5 \%)$ & $4(9 \%)$ \\
FH other & - & $6(27 \%)$ & $6(13 \%)$ \\
autoimmune disease & & & \\
\hline
\end{tabular}

Abbreviations: $C D$, celiac disease; $F$, female; $M$, male; $K$, Kuwaiti; NK, nonKuwaiti; FH, family history. 
in both groups and the majority were Kuwaitis. The NonKuwaitis included Middle Eastern Arabs and one Somali child. The mean age at diagnosis was $72.5 \pm 7.4$ months (median: 66; range: 7-189). Symptomatic patients were significantly younger than the screened with a mean age of $48 \pm 8$ (median: 24) and 101 \pm 9.7 (median: 92) months respectively $(P<0.004)$. Eleven $(23 \%)$ patients were less than 2 years; all were symptomatic.

None of the symptomatic group reported any autoimmune disease in themselves or their families. However, 4 (18\%) screened patients had other associated autoimmune disorders (hypothyroidism: 3, juvenile idiopathic arthritis: 1) and $6(27 \%)$ had a family history of diabetes (unspecified type). History of $\mathrm{CD}$ in a first degree relative was found in $9 \%$ of the whole group.

The most common presenting complaint in the symptomatic group was failure to thrive $(72 \%)$, followed by diarrhea (64\%) and abdominal distension (56\%). Other uncommon GI manifestations such as abdominal pain (36\%), anorexia (32\%), vomiting (24\%) and constipation (8\%) were also encountered. Atypical features such as mood changes, pallor and lower limb edema were found in $15(60 \%)$ symptomatic patients at presentation. The median duration of symptoms before diagnosis was 8.5 months (range: 2-54). A meticulous history from the screened group revealed that $10(45 \%)$ patients had recurrent attacks of mild nonspecific abdominal pain.

Complete anthropometric measurements at presentation were found in 36 patients; the majority had normal weight as shown in Table 2 and 19\%, mainly within the symptomatic group were underweight. Overweight and obesity were also detected in both groups. Short stature was confirmed in $17 \%$ of patients in both categories. A significant difference was

Table 2 Anthropometric measures

\begin{tabular}{lllll}
\hline & $\begin{array}{l}\text { Total } \\
\text { (N: 36) }\end{array}$ & $\begin{array}{l}\text { Symptomatic } \\
(\mathbf{N}: \text { 18) }\end{array}$ & $\begin{array}{l}\text { Screened } \\
\text { (N: 18) }\end{array}$ & $\begin{array}{l}\boldsymbol{P} \\
\text { value }\end{array}$ \\
\hline $\begin{array}{l}\text { Median weight } \\
\text { for age }\end{array}$ & -0.85 & -1.9 & -0.50 & 0.01 \\
$\begin{array}{l}\text { z score } \\
\text { Median height }\end{array}$ & -0.88 & -1.0 & & \\
for age & & & -0.23 & 0.27 \\
z score & & & & \\
Median body & -0.25 & -0.85 & -0.11 & 0.03 \\
mass index & & & & \\
for age & & & & \\
z score & & & & \\
Under weight & $7(19 \%)$ & $5(28 \%)$ & $2(11 \%)$ & 0.24 \\
$\begin{array}{l}\text { Normal weight } \\
\text { Overweight }\end{array}$ & $21(58 \%)$ & $9(50 \%)$ & $13(72 \%)$ & 0.06 \\
Obese & $5(14 \%)$ & $3(17 \%)$ & $2(11 \%)$ & 0.82 \\
\hline
\end{tabular}

detected between the 2 groups in the weight $z$ score $(z \mathrm{Wt})$ and BMI $z$ score $(z \mathrm{BMI})$ as $P$ was $<0.01$ and 0.03 respectively.

Laboratory evaluation revealed that anemia was the most prevalent feature in both groups. Biochemical abnormalities such as hypoalbuminemia, hypocalcemia and elevated liver enzymes were mainly found in the symptomatic patients. Nevertheless, the only statistically significant abnormality was elevated transaminases $(P<0.04)$. CD serology was done in all patients as a combination of EMA (positive in 85\%), AGA-IgA (positive in 79\%) and AGA-IgG (positive in 77\%). tTG was positive in all 9 tested patients. Total IgA level was not evaluated in all screened patients at presentation, however, it was normal in the tested cases.

The histopathology was consistent with Marsh 3 CD criteria in all biopsied patients in the form of prominent intraepithelial lymphocytes, crypt hyperplasia and either total or subtotal villous atrophy. Those having less than Marsh 3 changes were not included in this study to avoid equivocal changes. The lesions were patchy in the majority and continuous in few. No changes were confined to the bulb area in those who had bulb biopsy. We lack the histopathology evidence in one patient because of parental refusal of endoscopy. This patient presented with severe GI symptoms at 18 months associated with positive EMA and AGA that improved on gluten free diet (GFD).

Following diagnosis, all patients received dietary care and were commenced on GFD. The median follow up was 24 months (range: 12-144). Compliance on GFD was good in $78 \%$ of patients and non-adherence was mainly encountered in older screened children. Improvement of symptoms on GFD was documented in the symptomatic patients. Monitored CD serology was performed one-year post-GFD in $68 \%$ of patients using EMA. Gluten challenge was only done in the patient who refused intestinal biopsy 2 years after being asymptomatic on GFD. She experienced classical GI symptoms 4 weeks following gluten ingestion that were totally alleviated with reintroduction of GFD. Endoscopy was also refused during the challenge.

The average mid-year population of children $\leq 12$ years during the study period was 605,884 (based on the Public Authority for Civil Information of Kuwait). Therefore we estimated the cumulative incidence of CD among our children to be $6.9 \times 10^{5}$. Children $>12$ years ( 4 patients) were excluded from the calculation because the cut-off age for referral to the pediatric GI Unit in Kuwait is 12 years. Older patients are usually referred to the adult service. One patient was diagnosed prior to 1998 and hence was excluded from this 
calculation as well. The cumulative incidence in Kuwaiti children was $9.2 \times 10^{5}$.

\section{Discussion}

In this paper we report our experience with pediatric $C D$ in Kuwait over a 12-year period. All the cases in this study had positive serology plus biopsy proven $\mathrm{CD}$ except one because of parental refusal of endoscopy. The majority were Kuwaitis indicating the existence of the disease in our native population. Females were double the males, as reported in other populations. ${ }^{13,14}$ Most of the patients were diagnosed in the second half of the study period and this can be attributed to improved screening programs of high-risk groups.

Patients with T1D and Down's syndrome constituted the screened group in our study. Screening of other conditions recommended by ESPGHAN ${ }^{15}$ such as Williams syndrome, Turner's syndrome, autoimmune thyroid disease, autoimmune liver disease and selective IgA deficiency is not regularly performed by our physicians. Our T1D patients are screened annually based on the International Society of Pediatric and Adolescent Diabetes (ISPAD) guidelines, ${ }^{16}$ however, the prevalence of CD among T1D had not been reported in Kuwait. Nevertheless, the disease was reported in $2.4 \%$ of our local Down's syndrome population. ${ }^{17}$ Nine percent of our patients had $\mathrm{CD}$ in a first-degree relative. A higher number would be anticipated if family members were regularly screened, as recommended by ESPGHAN, ${ }^{15}$ which is not the case in our community.

The symptomatic patients were significantly younger than the screened and this might be attributed to the fact that younger patients usually present with classical symptoms that are easily recognized and hence investigated. In their earlier report about CD in Kuwait, Khuffash et al described young children with classical GI presentation that was associated with longer periods of missed symptoms. ${ }^{7}$ The shorter duration of symptoms before diagnosis in our group might be due to increased awareness of general pediatricians plus the current easy availability of serology and endoscopic evaluation in the country. Classical GI symptoms were reported in almost all cases of the earlier study while this was not the case in our series. ${ }^{7}$ Also, the significant presentation of atypical features in our symptomatic patients support the changing clinical identity of CD. In our screened patients; recurrent mild abdominal pain was a common complaint. Actually, an accurate analysis might disclose a variety of symptoms in screened patients who are supposed to be symptomless. In a large multicenter study on T1D children, $14.5 \%$ of diabetics displayed some symptoms, 13\% had GI and 1.3\% had atypical symptoms. ${ }^{18}$ In fact, our screened patients were older school children in whom recurrent abdominal pain is a common problem, which might not be related to CD. Underweight was detected in $28 \%$ of our symptomatic patients, in contrast to the earlier study when this was found in all patients. ${ }^{7}$ Most likely, the delay in diagnosing those earlier cases contributed to their growth failure. The difference between our groups in $z \mathrm{Wt}$ and $z \mathrm{BMI}$ is not surprising since the screened patients are supposed to be "healthy" individuals. Interestingly, overweight and obesity were also noticed in the symptomatic group. Reilly et al found that nearly $19 \%$ of North American CD children had an elevated BMI at diagnosis. ${ }^{19}$ An increased CD detection in overweight and obese children may represent the effect of serological screening of asymptomatic populations but also the current change of clinical presentation.

Regarding CD serology we depended mainly on EMA and AGA since tTG was unavailable until the end of the study period. The ESPGHAN working group on $\mathrm{CD}$ reported that IgA-tTG and EMA are the cornerstones of CD serology in children; ${ }^{20}$ hence, we are currently using those antibodies in our serological evaluation. Unfortunately, not all our screened patients were tested for total IgA level, which might have resulted in a false-negative serology in patients having low IgA.

Seventy eight percent of our patients were compliant to GFD. Adherence to GFD was more difficult in older screened children since they were also on restricted diet for their diabetes. Besides, those kids share meals with their peers at school or at social gatherings making it difficult to control food contamination. Commercially, GFD is scarcely available in the local market and when found, it is quite expensive. In addition, the labels on most of the packaged foods rarely mention their gluten content. Our patients are usually given some gluten-free products from the governmental hospitals but this is of limited variety and supply. Wheat is locally replaced by corn flour for making bread, which is nonpalatable to many kids.

In the patient who was challenged, the exact amount of gluten ingested was not defined but she consumed the normal daily gluten content taken by her family. CD was diagnosed based on classical symptoms, positive EMA and improvement on GFD in this child. Recurrence of symptoms following gluten challenge confirmed the diagnosis in spite of absence of positive histopathology.

Our increased number of cases compared to the 1987 report was mainly due to screening high-risk groups; 
nevertheless, this is probably not an absolute increase since the population more than tripled over the period. The exact prevalence in the community could not be determined because our study was not conducted in the general population; however, our estimated figure was much lower than that reported even in neighboring countries. ${ }^{21,22} \mathrm{CD}$ prevalence among low-risk populations in the Middle East was reported to be $0.14 \%-1.3 \%$ as assessed by serological markers and $0.033 \%-1.17 \%$ when assessed by biopsies. ${ }^{4}$

The daily wheat consumption in Kuwait is not officially defined but based on the report of the United States Department of Agriculture (USDA); the domestic consumption of wheat is rising in Kuwait. ${ }^{23}$ It went from 202,000 metric tons (MT) in 1987 to 380,000 MT in 2010 ( $88 \%$ rise). In the past, rice used to be the main source of nutrition in the country but there has been a great change in food items accepted by families over the past 2-3 decades. Increased meat and poultry consumption in Kuwait elevated the demand to use wheat. Foods like breads and pastas dominated the table in our country. Actually, the current Kuwaiti food is not different from that consumed by other Middle Eastern countries. This means that we should get an equivalent $\mathrm{CD}$ figure.

During the study period our unit was the only center providing endoscopy for children, therefore, all cases requiring a biopsy diagnosis should have been referred to us. This should make our estimated figure representative of the local pediatric population in Kuwait. However, we do believe that this is an underestimation of the exact number due to multiple reasons. Firstly, many local pediatricians are still unaware of the change of clinical presentation and rising atypical manifestations of CD. Secondly, screening high-risk groups including family members of established cases is not well adopted in our country. Thirdly, many pediatricians still depend on AGA testing that is not highly sensitive and specific..$^{20}$ Fourthly, total IgA level is not estimated in many patients specially the screened ones leading to negative CD serology. Efforts should be directed towards educating primary-care doctors, as well as pediatricians, regarding proper serology testing and interpretation to avoid false-negative results. The fifth point leading to our underestimated figure is the inclusion of only those with Marsh 3 changes. In addition, the bulb was not biopsied in all cases missing those with changes confined to that site. Together with the current local availability of tTG, Marsh 2 changes should be considered and the bulb should be biopsied in all patients. We believe that we are in need of a proper screening program to exactly determine the true prevalence in our country. By using salivary tTG in testing healthy primary school children, Nenna et al reported that
$66 \%$ of their CD patients were diagnosed by screening. ${ }^{24}$ This signifies the iceberg phenomenon of $\mathrm{CD}$ and certainly, a massive screening program could reduce the depth of the iceberg. HLA-DQ testing was not performed in our patients. Actually, the exact HLA typing in our general population is not defined. It will, indeed, be interesting to know the genetic susceptibility in a community characterized by a high degree of consanguinity.

\section{Conclusion}

$\mathrm{CD}$ exists in a very low frequency in our children although it has the same clinical features as reported in other populations. We believe that we are only reporting the tip of the iceberg and the actual disease figure is yet to be explored. The spectrum of disease presentation has changed over the years demanding more awareness by general pediatricians. Also, GFD represents a challenging problem in our country since gluten-free products are not commercially available. A campaign is needed to educate the public about this increasing global problem across all age groups especially with the current dietary modification of our local food and increasing gluten ingestion. A new $\mathrm{CD}$ association has been established recently in the country hoping to actively support patients and their families.

\section{Acknowledgments}

The authors would like to thank Mrs. Nada Yousef Mustafa for her efforts in performing the statistical analysis. Also, we would like to express our sincere appreciation to Professor Adekunle Adekile, Kuwait University, for revising the manuscript.

\section{Disclosure}

We declare that this manuscript is original, has not been published before and is not currently being considered for publication elsewhere. Also, we wish to declare that there is no conflict of interest associated with the study. This research was self-funded, with no external source of funding.

\section{References}

1. Rubio-Tapia A, Ludvigsson JF, Brantner TL, Murray JA, Everhart JE. The prevalence of celiac disease in the United States. Am J Gastroenterol. 2012;107(10):1538-1544.

2. Mustalahti K, Catassi C, Reunanen A, et al; for Coeliac EU Cluster, Project Epidemiology. The prevalence of celiac disease in Europe: results of a centralized, international mass screening project. Ann Med. 2010;42(8):587-95.

3. Cataldo F, Montalto G. Celiac disease in the developing countries: A new and challenging public health problem. World $J$ Gastroenterol. 2007;13(15):2153-2159. 
4. Barada K, Bitar A, Mokadem MA, Hashash JG, Green P. Celiac disease in Middle Eastern and North African countries: A new burden? World J Gastroenterol. 2010;16(12):1449-1457.

5. Saadah OI. Celiac disease in children and adolescents at a single center in Saudi Arabia. Ann Saudi Med. 2011;31(1):51-57.

6. Al-Lawati TT, Al-Musawi HS. Celiac Disease in Oman: A Tertiary Centre Experience. Oman Med J. 2013;28(1):70-72.

7. Khuffash FA, Barakat MH, Shaltout AA, Farwana SS, Adnani MS, Tungekar MF. Coeliac disease among children in Kuwait: difficulties in diagnosis and management. Gut. 1987;28(12):1595-1599.

8. Shaltout AA, Khuffash FA, Hilal AA, el Ghanem MM. Pattern of protracted diarrhoea among children in Kuwait. Ann Trop Paediatr. 1989;9(1):30-32.

9. Hill ID, Dirks MH, Liptak GS, et al. Guideline for the diagnosis and treatment of celiac disease in children: recommendations of the North American Society for Pediatric Gastroenterology, Hepatology and Nutrition. J Pediatr Gastroenterol Nutr. 2005;40(1):1-19.

10. Kuczmarski RJ, Ogden CL, Guo SS, et al. 2000 CDC growth charts for the United States: methods and development. Vital Health Stat 11. 2002;(246):1-190.

11. Wang Y, Chen H-J. Use of percentiles and Z-scores in anthropometry. In: Preedy VR, editor. Handbook of Anthropometry: Physical Measures of Human Form in Health and Disease. New York: Springer Science + Business Media, LLC; 2012:29-48.

12. Marsh MN. Gluten, major histocompatibility complex, and the small intestine. A molecular and immunobiologic approach to the spectrum of gluten sensitivity ('celiac sprue'). Gastroenterology. 1992;102(1):330-354.

13. Ivarsson A, Persson LA, Nyström L, Hemell O. The Swedish coeliac disease epidemic with a prevailing twofold higher risk in girls compared to boys may reflect gender specific risk factors. Eur J Epidemiol. 2003;18(7):677-684.

14. Roma E, Panayiotou J, Karantana H, et al. Changing pattern in the clinical presentation of pediatric celiac disease: a 30-year study. Digestion. 2009;80(3):185-191.

15. Husby S, Koletzko S, Korponay-Szabó IR, et al; for ESPGHAN Working Group on Coeliac Disease Diagnosis. European Society for Pediatric Gastroenterology, Hepatology, and Nutrition guidelines for the diagnosis of coeliac disease. J Pediatr Gastroenterol Nutr. 2012;54(1):136-160.
16. Kordonouri O, Maguire AM, Knip M, et al. Other complications and associated conditions with diabetes in children and adolescents. Pediatr Diabetes. 2009;10 Suppl 12:S204-S210.

17. Hamadi K, Al Ateeqi W, Al Awadi S, Hamadi T. Prevalence and clinical manifestation of celiac disease in Down syndrome patients in Kuwait. New Egypt J Med. 2010;43:204-209.

18. Cerutti F, Bruno G, Chiarelli F, Lorini R, Meschi F, Sacchetti C; for the Diabetes Study Group of the Italian Society of Pediatric Endocrinology and Diabetology. Younger age at onset and sex predict celiac disease in children and adolescents with type 1 diabetes: an Italian multicenter study. Diabetes Care. 2004;27(6):1294-1298.

19. Reilly NR, Aguilar K, Hassid BG, et al. Celiac disease in normalweight and overweight children: clinical features and growth outcomes following a gluten-free diet. J Pediatr Gastroenterol Nutr. 2011;53(5):528-531.

20. Giersiepen K, Lelgemann M, Stuhldreher N, et al; for ESPGHAN Working Group on Coeliac Disease Diagnosis. Accuracy of diagnostic antibody tests for coeliac disease in children: summary of an evidence report. J Pediatr Gastroenterol Nutr. 2012;54(2):229-241.

21. Tack GJ, Verbeek WH, Schreurs MW, Mulder CJ. The spectrum of celiac disease: epidemiology, clinical aspects and treatment. Nat Rev Gastroenterol Hepatol. 2010;7(4):204-213.

22. Gujral N, Freeman HJ, Thomson AB. Celiac disease: Prevalence, diagnosis, pathogenesis and treatment. World J Gastroenterol. 2012;18(42):6036-6059.

23. United States Department of Agriculture (USDA), Foreign Agricultural Service, Production, Supply and Distribution Online [home page on the Internet]. Grain World Markets and Trades, [updated 2014 August 12]. Available from: http://www.fas.usda.gov/psdonline/psdhome.aspx. Accessed August 14, 2014.

24. Nenna R, Tiberti C, Petrarca L, et al. The celiac iceberg: characterization of the disease in primary schoolchildren. J Pediatr Gastroenterol Nutr. 2013:56(4):416-421.
Clinical and Experimental Gastroenterology

\section{Publish your work in this journal}

Clinical and Experimental Gastroenterology is an international, peerreviewed, open access journal, publishing all aspects of gastroenterology in the clinic and laboratory, including: Pathology, pathophysiology of gastrointestinal disease; Investigation and treatment of gastointestinal disease; Pharmacology of drugs used in the alimentary tract;

\section{Dovepress}

Immunology/genetics/genomics related to gastrointestinal disease. This journal is indexed on CAS. The manuscript management system is completely online and includes a very quick and fair peer-review system. Visit http://www.dovepress.com/testimonials.php to read real quotes from published authors. 